\title{
Entre o atender e o ser atendido: políticas em saúde para o trabalhador do serviço público
}

\author{
Zelma Borges de Souza ${ }^{1}$ e Lélia Marília dos Reis ${ }^{2}$ \\ Secretaria da Fazenda do Estado da Bahia (Salvador, BA)
}

As relações do mundo do trabalho repercutem nos processos saúde/doença do servidor público. Nosso propósito foi compreender como são percebidas as políticas em saúde do trabalhador do serviço público. Apresentamos relatos de representantes de sete instituições públicas de um município do sudoeste da Bahia. Os relatos foram mediados a partir da seguinte questão norteadora: "Fale-me de sua experiência na área da saúde do trabalhador e como você percebe essa política no município e no órgão no qual você está inserido". Os dados foram analisados a partir do método fenomenológico, tendo emergido sete categorias: 1) estruturação dos serviços: institucionalizar os serviços na rede de saúde municipal; 2) ações e diretrizes: divulgação sobre o tema; 3) equipes e serviços: registro de adoecimentos relacionados ao trabalho; 4) atenção à saúde do servidor público por meio de políticas públicas: carência de ações; 5) principais demandas em saúde do trabalhador: LER-DORT, transtornos mentais; 6) limites e dificuldades: burocracia, mudanças de gestores; 7) Ausência de protocolo e planejamento: ações pontuais. Conclusão: necessidade de ampliação de ações visando à saúde do servidor público e dar visibilidade a essa necessidade, por meio de dados mensuráveis e de divulgação. Indicação de ampliação de espaço para discussão dentro das instituições públicas.

Palavras-chave: Políticas públicas, Saúde do trabalhador, Servidor público.

Between the meeting and being met: health policy for public service workers

The relationships in the work world reflect upon the health/disease processes of public servants. Our purpose was to comprehend how the policies within Public Service Occupational Health are viewed. We present reports by representatives of seven public institutions from a municipality in southwestern Bahia. The reports were mediated from the following question: "Tell me about your experience in the occupational health field and how you view this policy in the municipality and in the agency in which you are". Data were analyzed through the phenomenological method with the emergence of seven categories: 1) structuring of services: institutionalization of services in the municipal health network; 2) actions and guidelines: diffusion on the subject; 3) teams and services: registration of work-related illnesses; 4) health care for public servants by means of public policies: lack of actions. 5) main occupational health demands: RSI/WRMSD, mental disorders; 6) limits and difficulties: bureaucracy, managers' replacements; 7) lack of protocol and planning: specific actions. Conclusion: need for expanding actions by aiming at public servants' health and providing visibility for this need through measurable data and diffusion. Indication of larger space for discussion within public Institutions.

Keywords: Public policies, Occupational health, Public servant.

\section{Pré-reflexivo}

$\mathrm{P}$ ercorremos um caminho que nos conduziu a buscar a compreensão do fenômeno das políticas em saúde para o trabalhador do serviço público. O interesse pelo tema emergiu com os estudos na disciplina Saúde do Trabalhador, oferecida na graduação em Psicologia. A escolha do tema aconteceu também pela aproximação do assunto com a vida profissional da pesquisadora, que atua como servidora pública. A partir do contato com pessoas que trabalham nessa área, foi possível observar a incidência de adoecimento físico e psíquico, além do adoecimento de muitas pessoas que nem sempre encontram tratamento adequado ou

1 Psicóloga, Secretaria da Fazenda do Estado da Bahia.

2 Doutora em Psicologia pela FFCLRP/USP e Mestre em Ciências Médicas pela FMRP/USP. Pesquisadora do grupo SexualidadeVida - CNPq/USP. 
informações que permitam a compreensão do que sentem, de forma que possam lidar melhor com o sofrimento relacionado ao trabalho.

A administração dos serviços públicos abrange uma extensa área de atividades e uma vasta gama de formas de execução. O servidor público trabalha em benefício da coletividade, e muitos servidores exercem a função de fiscalizar as condições de trabalho de outras pessoas, visando à promoção e à proteção da saúde. Este estudo tem a intenção de conhecer mais sobre a saúde desse trabalhador, pois entendemos que o serviço público exige o cumprimento de regras definidas e formalidades expressas, com rigidez e alto grau de controle, que podem refletir no indivíduo, repercutindo no processo saúde/doença. Adiciona-se a esses aspectos a experiência de lidar com o público, que traz demandas diversas.

Reconhecemos que os trabalhadores privados também sofrem e que têm carência de políticas em saúde, mas, diante do exposto e uma vez que são propostas políticas públicas para o setor público, quisemos averiguar como os trabalhadores percebem essas políticas e, nesse sentido, como as ações e as produções sobre o tema da saúde do servidor alcançam servidores das esferas municipal, estadual e federal. Portanto, é o servidor público e os investimentos em sua saúde - por meio de políticas públicas - que compõem nossas indagações, tendo como objetivo específico o fenômeno investigado: como são percebidas as políticas em saúde do trabalhador do serviço público por servidores públicos de uma região do sudoeste da Bahia.

Para permitir a compreensão desse fenômeno, traçaremos, neste artigo, o seguinte trajeto: inicialmente, apresentaremos uma exposição sobre o mundo do trabalho e, em especial, o do servidor público. Em seguida, discutiremos o conceito de saúde e as relações desta com o trabalho. Buscaremos contextualizar a área de saúde do trabalhador no Brasil e, especificamente, a do servidor público, expondo sobre as políticas existentes, sua história, organização e o funcionamento dos serviços correspondentes.

$\mathrm{Na}$ sequência, faremos a apresentação do método desta pesquisa. Em seguida, apresentaremos a análise compreensiva dos relatos, relacionando-se com as reflexões teóricas. Por fim, apresentaremos nossa conclusão, fazendo uma reflexão acerca das possibilidades de ampliação dos cuidados com a saúde do trabalhador do serviço público.

\section{Contextualização do fenômeno}

\section{O mundo do trabalho}

A reestruturação produtiva, a internacionalização e abertura das economias e a integração mundial dos mercados são conformações econômico-político-sociais que vêm causando profundas transformações nas relações de trabalho, conforme Merlo e Lapis (2007). Segundo estes autores, tais mudanças se ampliam a partir dos anos 1970, quando teve início a Terceira Revolução Tecnológica, que ainda está em curso.

O trabalho ocupa grande parte da vida, permite o estabelecimento de relações e maior ou menor valorização social. Antunes (2005) afirma que, no capitalismo contemporâneo, o trabalho permanece com papel central nas relações sociais e na manutenção do capitalismo, e que as transformações que aconteceram, como as da tecnologia e as da informática, apenas trouxeram mudanças nas formas de exploração e acumulação do capital. Pesquisas sobre essas novas relações de trabalho apontam para um agravamento do adoecimento do trabalhador: "As profundas transformações do modelo econômico vêm atingindo, de forma acelerada e diferenciada, sobretudo na última década, amplos setores da população trabalhadora" (Gomez $\&$ Thedim-Costa, 1999, p. 412). 
O mundo do trabalho atual preconiza uma noção de competência que traz em seu bojo o aumento da pressão e da competição, além da exploração da subjetividade do indivíduo. De acordo com Machado (2007), "dos trabalhadores, além do encargo de alimentar as máquinas, passou-se a demandar a mobilização subjetiva de seus recursos pessoais - saberes, capacidades e atitudes - como condição de participação e integração na nova dinâmica produtiva” (p. 282). Sennett (1999) aborda a flexibilização das relações de trabalho, que traz consequências para o trabalhador - como a exigência de ser polivalente, a perda de direitos trabalhistas e o aumento da jornada de trabalho -, que, muitas vezes, são estendidas ao espaço de fora do trabalho, gerando insegurança e influenciando suas relações.

Mendes e Araújo (2011) denunciam a perversão dos novos modelos de gestão e seus efeitos sobre a saúde dos trabalhadores, salientando o desamparo e a solidão, originados das falsas promessas da gestão pautada na qualidade total, na ideologia da excelência e na lógica produtivista: "Os modos de organização do trabalho, no contexto do capital flexível, têm conduzido à desestruturação dos coletivos de trabalho, a uma carência de solidariedade e confiança e a um enfraquecimento dos laços sociais" (Mendes \& Araújo, 2011, pp. 15-18).

Antunes (2005) aponta que a precarização das relações de trabalho aliena e infelicita o ser social e que é essencial o reconhecimento dessas relações para que o trabalho exerça seu potencial emancipador. Compreendemos que esses autores abordam a questão da captura da subjetividade e da necessidade de compreensão dessas relações, de forma que articulam-se com Dejours (1992), quando este analisa que a experiência no mundo do trabalho pode gerar o pior e o melhor, mas que isso depende da capacidade de pensar as relações entre subjetividade, trabalho e ação.

\section{O mundo do trabalho do servidor público}

Objetivando conhecer as peculiaridades da administração pública e do mundo do servidor público, buscamos uma compreensão da estrutura organizacional do Estado.

Meirelles (2008) explica que a estrutura da administração pública compreende a administração direta e a administração indireta; a primeira compõe-se de órgãos com subordinação direta ao executivo, que são os Ministérios, as Secretarias de Estado e as Secretarias Municipais, respectivamente, das esferas federal, estadual e municipal. A administração indireta compreende a atividade administrativa dos serviços públicos do Estado transferida para outra entidade por ele criada: são as autarquias, as fundações e as empresas públicas. Nestes espaços denominados "instituições públicas", atuam os trabalhadores do setor público ou servidores públicos. Para Dallari (1989), "servidor público é quem trabalha para a administração pública em caráter profissional, não eventual, sob vínculo de subordinação e dependência, recebendo remuneração paga diretamente pelos cofres públicos" (pp. 15-17). O ingresso desse servidor no serviço público acontece de maneira formal, por meio de regras estabelecidas, mediante concurso público, como prescreve o artigo 37, inciso II, da Constituição da República Federativa do Brasil (Brasil, 2006).

No entanto, acompanhando as mudanças ocorridas com a reestruturação produtiva, depois da década de 1970, surgem novas formas de ingresso no serviço público, coexistindo uma variedade de categorias e formas diversas de vínculo empregatício, como o concursado, o ocupante de cargo de confiança e o prestador de serviço contratado por terceirização.

\section{Saúde do trabalhador}

Percebemos que o tema saúde do trabalhador tem sido objeto de estudos e investimentos em setores que compreendem a necessidade de investir na promoção da saúde dos empregados, com o objetivo de obter melhoria no seu desempenho e no desempenho da 
organização. Conceitos como qualidade de vida, ergonomia e programas de promoção da saúde têm sido introduzidos no cotidiano das organizações. Constata-se que vários fatores podem ter influência na saúde do trabalhador. Em consequência, ampliam-se os desafios e as dificuldades com relação a um programa nacional de segurança e saúde do trabalhador, seja este do setor privado ou do setor público: "Há avanços na universalidade e na descentralização de saúde, especialmente com a municipalização das ações e dos serviços. Mas ainda estamos a passos lentos quanto ao acesso, em razão da imposição de obstáculos para utilizar os serviços" (Brasil, 2011).

Saúde é um tema abrangente, que pode ser enfocado sob vários aspectos. Partimos do entendimento de saúde com uma visão que ressalta os recursos sociais e pessoais e ultrapassa o conceito de ausência de doença. Utilizamos, para fundamentar esse entendimento, contribuição de Christophe Dejours ${ }^{3}$, sobre a relação saúde e trabalho. Ao estudar como algumas pessoas conseguem não adoecer nas relações de trabalho, ele argumenta que existem algumas qualidades psíquicas que permitem o desempenho de determinadas funções que evitam o adoecimento (Dejours, 1992). Ele amplia a compreensão sobre saúde e a relaciona ao trabalho, ao afirmar:

A saúde, então, não é um estado natural, mas uma construção intencional, na qual o trabalho ocupa lugar importante. A construção da saúde está ligada a uma série de relações. De um lado, as relações interindividuais, para a construção da saúde no registro do amor; de outro, as relações intersubjetivas coletivas, no campo do trabalho. A saúde de uma pessoa depende muito de seus colegas, assim como suas doenças. Nossa capacidade de resistir ou de ficar doente está intimamente relacionada à qualidade das relações de trabalho (Dejours, 1999, p. 98).

Nosso estudo parte da compreensão do processo saúde-doença do homem em sua relação com o trabalho como um fenômeno que sofre influência da cultura, da política, da economia e dos processos sociais mais amplos, conforme visão de Dejours (1986), para quem a saúde compreendida como um estado é um equívoco. Sato, Lacaz, Bernardo (2006) e outros autores abordam igualmente a questão da saúde/doença e qualidade de vida no trabalho com uma perspectiva ampliada, que ultrapassa visões consideradas como limitadas:

[...] a abordagem assistencialista e hegemônica não dá conta de enfrentar as causas reais e mais profundas das fontes de mal-estar dos trabalhadores... o modo mais apropriado para se construir uma concepção, baseada na realidade das organizações contemporâneas, é perguntar aos próprios trabalhadores, a todos os que atuam numa dada organização (Ferreira, 2011, pp. 109-110).

Considerando o atual mundo do trabalho, com relação ao trabalhador do serviço público, Domingues Júnior (2005) avalia: "possuímos hoje um Estado muito mais complexo, abrangendo um sem número de atividades econômicas, que oferecem uma ampla gama de riscos à saúde e à segurança do trabalhador no serviço público" (p. 55). Santos-Filho (2007) discute as adversidades inerentes a esse setor:

[...] a própria instabilidade e adversidades habituais no trabalho no setor público [...] mobilizam e desestabilizam os investimentos e interesses dos trabalhadores, incessantemente provocando e desafiando [...] mesclando-se perspectivas e saídas "criativas", "inventivas", e também desgastantes, geradoras de sofrimento (p. 2).

A argumentação apresentada por esse autor sobre "perspectivas e saídas criativas", coexistindo com perspectivas e saídas "desgastantes", articula-se com Dejours (1992), ao

3 Dejours é médico do trabalho, psiquiatra e psicanalista. Propôs a "psicodinâmica do trabalho", a partir dos anos 1980 na França, e estuda com um olhar amplo e integrador a organização do trabalho e seus impactos sobre a saúde do trabalhador. 
referir-se à forma como os trabalhadores enfrentam situações de angústia e insatisfação decorrentes do trabalho. Entendemos que a existência de espaços de discussão e busca de compreensão são saídas produtivas, enquanto algumas alternativas ampliam o sofrimento por serem produzidas defesas individuais, como a competição entre os trabalhadores ou até o processo de culpabilizar-se por não conseguir lidar com as situações e adoecer. Investigar junto ao servidor público a percepção que este tem sobre o tema da saúde do servidor coincide com a proposta de Dejours, ao permitir que aconteça o processo de busca da compreensão por meio da fala.

Para uma maior compreensão do fenômeno analisado, traçaremos um perfil da área de saúde do trabalhador no Brasil.

\section{Políticas de saúde do trabalhador no Brasil}

O conceito de saúde do trabalhador surgiu como uma prática instituinte, com a proposta de transformar e compreender o processo saúde-doença nos trabalhadores, na década de 1980 (Sato et al., 2006), quando, segundo Lacaz (2005), aconteceu o processo da Reforma Sanitária Brasileira ${ }^{4}$ e a sociedade debateu amplamente o conceito de saúde. A relação do trabalho com a saúde foi reconhecida como uma questão de saúde pública, sendo incluída na Constituição de 1988 como responsabilidade do Sistema Único de Saúde (SUS), com a determinação de integrar as ações de vigilância dos ambientes de trabalho às de atenção à saúde dos trabalhadores. Desse processo também resultou a 1ํㅡㄹ Conferência Nacional de Saúde do Trabalhador (CNST) (1986), a Assembleia Nacional Constituinte e a Constituição Federal de 1988, a Lei Orgânica da Saúde, de 1990 e a 2ª e a 3a CNST. Com a criação do SUS em 1988, a partir de 1990, ocorreu a regulamentação da organização e do funcionamento dos serviços de saúde (Lacaz, 2005; Sato et al., 2006).

Toda essa construção trouxe grandes avanços para a área de saúde do trabalhador, por permitir discussões e resultar em uma ampliação de conceitos e objetivos. Uma vez definidos o arcabouço e as intenções para a área, o processo encaminhou-se no sentido da estruturação da área de atenção à saúde do trabalhador no SUS, sendo definida em 2002, pela Portaria 1.679/GM, a composição da Rede Nacional de Atenção Integral à Saúde do Trabalhador no SUS (RENAST), que responde pela execução de ações curativas, preventivas, de promoção e de reabilitação à saúde do trabalhador brasileiro. A RENAST é composta por 178 Centros Estaduais e Regionais de Referência em Saúde do Trabalhador (CEREST) ${ }^{5}$ e por uma Rede Sentinela de serviços médicos e ambulatoriais de média e alta complexidade responsáveis por diagnosticar os acidentes e as doenças relacionados ao trabalho e por registrá-los no Sistema de Informação de Agravos de Notificação - SINAN-NET (Brasil, 2010a). Componente importante da área de atenção à saúde do trabalhador, a Vigilância em Saúde do Trabalhador (VISAT), vinculada ao Ministério da Saúde, dirige ações de prevenção de agravos e promoção da saúde do trabalhador. ${ }^{6}$

\footnotetext{
4 Paim (2007) diz que a conquista da democracia em 1985 é que possibilitou o reconhecimento da saúde como um direito de todos e dever do Estado, recomendando-se a organização de um Sistema Único de Saúde descentralizado e democrático. Diz que esse processo de democratização de saúde, naquela época, denominou-se Reforma Sanitária.

5 Portaria 1.679/GM, 2002 define: São dois os tipos de CERESTs: estaduais e regionais. Cabe aos CEREST regionais capacitar a rede de serviços de saúde, subsidiar a formulação de políticas públicas, apoiar a estruturação da assistência para atender aos acidentes de trabalho e agravos contidos na Lista de Doenças Relacionadas ao Trabalho e aos agravos de notificação compulsória. Os CERESTs estaduais elaboram e executam a Política Estadual de Saúde do Trabalhador, acompanham a definição da Rede Sentinela e a contribuição para as ações de vigilância em saúde (Brasil, 2010b).

6 Tem como metas: 1) Mapear o parque produtivo do município, quantificando as atividades econômicas e seus trabalhadores; 2) Implantar a Notificação Compulsória dos Agravos de Saúde do Trabalhador de acordo com a Portaria GM 777/2004; 3) Investigar os óbitos notificados no SINAM com causa mortis "Acidente de Trabalho"; 4) Implantar a Vigilância em Saúde do Trabalhador através das fiscalizações nos ambientes de trabalho normatizada pela Portaria GM 3.120/1998 (Brasil, 2010d).
} 
Integrando atividades e setores, em maio de 2005, a Portaria Interministerial no 800 publicou o texto-base da minuta da Política Nacional sobre Saúde e Segurança do Trabalho (PNSST). Esta política é desenvolvida em esfera interinstitucional pelo Ministério da Saúde, integrada com o Ministério do Trabalho e Emprego e com o Ministério da Previdência Social. Compreende a atenção integral à saúde, a articulação intra e intersetorial, a participação popular, o apoio a estudos e a capacitação de recursos humanos (Brasil, 2010c).

A Política Nacional sobre Saúde e Segurança do Trabalho é descentralizada entre estados e municípios. Na Bahia, a Secretaria da Saúde do Estado (SESAB) mantém o Programa de Atenção à Saúde do Trabalhador e as seguintes unidades a ela vinculadas: Diretorias Regionais de Saúde (DIRES); Centro Estadual em Referência à Saúde do Trabalhador (CESAT), criado em 1988 para atender às necessidades de assistência e prevenção de doenças ocupacionais e acidentes de trabalho no âmbito do estado; Núcleos de Saúde do Trabalhador (NUSAT), que existem em alguns municípios e representam o CESAT. Buscamos, dessa forma, contextualizar a área de Saúde do Trabalhador, para ampliar a visão sobre essa realidade, demarcando as políticas existentes e o funcionamento dos serviços (Bahia, 2010).

\section{Políticas e discussões sobre a saúde do trabalhador do serviço público no Brasil}

Buscando identificar novos referenciais sobre a saúde do trabalhador do serviço público, identificamos ações que estão sendo desenvolvidas no âmbito do funcionalismo público federal. O Ministério de Planejamento lançou uma política que se expande entre os estados da federação: em 2009, foi instituído pelo Decreto no 6833 o SIASS - Subsistema Integrado de Atenção à Saúde do Servidor, que reúne áreas de recursos humanos de órgãos do Poder Executivo, de órgãos federais dos estados e técnicos dos serviços de saúde, buscando construir uma Política de Atenção à Saúde (Brasil, 2012a).

Para implementar a política, disseminar informações e capacitar os profissionais da rede SIASS, foram realizados Encontros Nacionais de Atenção à Saúde do Servidor - ENASS. Em outubro de 2012 aconteceu o IV ENASS, abordando temas como a capacitação em Qualidade de Vida no Trabalho - QVT para a promoção da saúde dos servidores e o fortalecimento do SIASS (Brasil, 2012b). No estado da Bahia, existem unidades SIASS no Ministério da Fazenda e na Universidade Federal da Bahia - UFBA, em Salvador (Brasil, 2012c).

Ao buscar aprofundar o conhecimento sobre o tema de saúde do servidor público, identificamos pesquisa da Universidade de Brasília (UNB), sobre gestão de qualidade de vida no trabalho (QVT) no serviço público federal, que investigou as práticas de QVT em dez órgãos públicos federais e apontou que permanecem pouco exploradas, sendo detectada uma abordagem de viés assistencialista, que tem no trabalhador a variável de ajuste (Ferreira, Alves $\&$ Tostes, 2009).

Foi criado no ano de 2007 o Laboratório de Psicodinâmica e Clínica do Trabalho (LPCT), na Universidade de Brasília. O LPCT realiza pesquisas e desenvolve a clínica psicodinâmica do trabalho em empresas públicas e privadas, com base na clínica do trabalho e da ação conforme postulada por Dejours (1992). Mendes e Araújo (2011) apresentam a trajetória brasileira dessa prática e assinalam que as experiências em organizações privadas e públicas encontraram diversas limitações, mas que abrem a possibilidade de o trabalhador pensar nas relações de trabalho e de perceber que tem um papel a desempenhar nesse cenário. Outras produções realizadas no LPCT apontam que, no âmbito científico, a produção bibliográfica sobre QVT, na ótica dos trabalhadores, é incipiente (Ferreira, Antloga, Ferreira \& Bergamaschi, 2009). 


\section{Objetivos}

Conforme já explicitado, esta pesquisa objetiva perceber como as políticas propostas são percebidas por servidores públicos de uma região do sudoeste da Bahia e, nesse sentido, como ações desenvolvidas no âmbito do funcionalismo público federal e as produções sobre o tema da saúde do servidor alcançam estes servidores das esferas municipal, estadual e federal.

\section{Metodologia}

\section{Pesquisa fenomenológica}

Em busca de um caminho que nos conduzisse até o fenômeno investigado - como são percebidas as políticas em saúde do trabalhador do serviço público -, elegemos a modalidade fenomenológica de pesquisa, por permitir acesso ao vivido, estando "voltada para o estudo da realidade social enquanto vivida na sua vida cotidiana", conforme Capalbo (1980) citado por Simões e Souza (1997, p. 13). Essa modalidade possibilita a apreensão do fenômeno que se manifesta, se mostra à consciência do sujeito que o questiona, conforme explicam Oliveira e Cunha (2006). Nesse sentido, nossa busca é a de perceber a realidade desvelada por cada entrevistado.

Godoy (1995) aponta que "a abordagem qualitativa, enquanto exercício de pesquisa, não se apresenta como uma proposta rigidamente estruturada, ela permite que a imaginação e a criatividade levem os investigadores a propor trabalhos que explorem novos enfoques" (p. 23).

De acordo com Martins (1992), citado por Oliveira e Cunha (2006), na busca da essência do fenômeno, tem-se a redução fenomenológica ou epoché, que significa "suspender", colocar "entre parênteses" os pressupostos, as crenças ou as teorias acerca do fenômeno que está sendo interrogado. Essa postura do investigador possibilita que o fenômeno se mostre tal como é e ocorra a análise compreensiva dos relatos.

Como estratégia de acesso ao fenômeno, utilizamos a entrevista aberta, que foi encaminhada por meio da seguinte questão norteadora: "Fale-me de sua experiência na área da saúde do trabalhador e como você percebe essa política no município e no órgão no qual você está inserido".

A partir dessa questão, foram surgindo os relatos, sendo registrados por meio de gravação e, posteriormente, transcritos. Em seguida, para a compreensão do fenômeno acessado e eleição dos relatos, buscamos a análise compreensiva com base nos passos sugeridos por Amatuzzi (2001) e Bruns (2007), citados por Reis (2010):

- Leitura da descrição inteira (entrevista transcrita), com vistas a compreender o todo do fenômeno apresentado;

- Releitura da descrição, apreendendo e identificando unidades de significado;

- Expressão do sentido contido nas unidades de significado, em especial nas que melhor desvelam o fenômeno considerado;

- Síntese das unidades de significado, suas convergências e divergências, para chegar à compreensão do fenômeno. 


\section{Acesso aos entrevistados}

Selecionamos um grupo de sete instituições públicas de um município do sudoeste da Bahia, que estão sujeitas a políticas e regulamentações semelhantes. Os sujeitos da pesquisa foram membros da alta administração ou coordenadores de áreas voltadas para a saúde do trabalhador.

A coleta de informações ocorreu no período de outubro a novembro de 2012; as entrevistas foram agendadas com antecedência e realizadas na própria instituição, depois de os entrevistados terem assinado o Termo de Consentimento Livre e Esclarecido (Anexo I da Resolução CNS 196/96) e de terem recebido as informações necessárias, especialmente sobre o sigilo da identidade e a liberdade caso quisessem desistir da entrevista. Visando manter o anonimato dos entrevistados, eles são mencionados neste artigo por E1, E2, E3, E4, E5, E6, e E7.

\section{Eleição das categorias}

Como resultado da busca de compreensão dos relatos, que fez surgir convergências e divergências, elegemos um conjunto de sete unidades de significado, as quais denominamos categorias:

- Categoria 1 - Estruturação dos serviços: Analisamos o panorama da área de saúde do trabalhador no estado da Bahia, especialmente na região sudoeste, e identificamos o que revelam os entrevistados com relação à estrutura dos serviços;

- Categoria 2 - Ações e diretrizes: Analisamos, a partir dos relatos dos entrevistados, o desenvolvimento das ações em saúde do trabalhador e quais diretrizes são consideradas mais importantes;

- Categoria 3 - Equipes e serviços: Apresentamos as equipes e os serviços que são desempenhados na região sudoeste, a partir da percepção dos entrevistados;

- Categoria 4 - Atenção à saúde do servidor público por meio de políticas públicas: Buscamos analisar como os entrevistados percebem as políticas públicas em saúde do trabalhador;

- Categoria 5 - Principais demandas em saúde do trabalhador: Analisamos as carências e as demandas percebidas como principais pelos entrevistados com relação à saúde do servidor público;

- Categoria 6 - Limites e dificuldades: Expõem-se os limites e as dificuldades para a implantação de ações em saúde do trabalhador, apontados nas entrevistas. Há aqui uma subcategoria: burocracia;

- Categoria 7 - Ausência de protocolo e planejamento: São os depoimentos que evidenciam a ausência de um planejamento ou de um protocolo para lidar com a saúde do trabalhador.

\section{Análise compreensiva}

Feita a definição das categorias, segue-se a análise compreensiva dos relatos de representantes de áreas voltadas para a saúde do trabalhador de sete instituições públicas de um município do sudoeste da Bahia, relacionando-se com as reflexões teóricas. 


\section{Categoria 1: Estruturação dos serviços}

Então é como se o sistema funcionasse assim: Ministério da Saúde, com a política nacional. Na Bahia, a gente tem o CESAT, os CERESTs e as unidades sentinela, que são os municípios, também, que devem estar desenvolvendo suas ações relacionadas à proteção à saúde do trabalhador [...] Porque, na realidade, eles não têm a vigilância de saúde do trabalhador implantada ainda, o Programa. [...] o que a gente quer é que esses profissionais tenham a capacidade de estar interferindo pra que esse problema vá para o plano municipal de saúde, por exemplo, que é o instrumento de gestão que vai nortear a política do município [...] pra que aquele município desenvolva ações para aquela área (E1).

A macro e a micro de Vitória da Conquista possuem apenas o CEREST de Vitória da Conquista (E7).

O entrevistado refere-se à falta de implantação do Programa de Vigilância em Saúde do Trabalhador, das unidades sentinela e da necessidade de que as ações sejam institucionalizadas nas prefeituras municipais. Compreendemos que a proposta de que a Atenção à Saúde do Trabalhador funcione como uma rede nacional torna-se prejudicada se os membros que integram esta rede não assumem a sua parte.

Com a publicação da Resolução CIB 84/2011 da Secretaria de Saúde do Estado, todos os municípios da Bahia devem se responsabilizar por desenvolver ações de saúde do trabalhador em seus territórios, ainda que sejam ações simples. Contudo, os municípios ainda não estão realizando estas ações (E7).

Lacaz (2000) aponta uma proposta nesse sentido, em artigo do DIESAT ${ }^{7}$, sugerindo mudanças na proposta do SUS, em relação ao modelo de centros de referência. Segundo o autor, ações em saúde do trabalhador devem fazer parte da prática diária na rede municipal:

[...] pensar a proposta de saúde do trabalhador no SUS sob a ótica de se envolver a rede básica de saúde. Também vejo a urgência de revisão do modelo de centros de referência [...] a rede municipal deve incorporar na sua prática diária (Lacaz, 2000, p. 2).

Com relação à região sudoeste, é evidenciada preocupação pela constatação de que a estrutura está bem aquém da necessária. Os depoimentos revelam que, em toda a Bahia, as equipes trabalham nas prioridades. É assinalada a urgência da implantação de mais CERESTs para atender às graves demandas existentes na região sudoeste:

Então realmente tem uma equipe mínima para a região sudoeste [...]. Então já caberiam mais dois CERESTs. Pelo menos, acho que um em Brumado ou em Guanambi, não sei, mas é uma necessidade urgente, porque o CEREST [...] não tem como, ele tem que dar conta [...] e com uma equipe mínima (E1).

O CEREST é um centro de referência, e essa referência na área de abrangência nossa é muito grande. Nós temos 73 municípios que atendemos, e realmente tá sendo complicado (E7).

O entrevistado informa não ser possível precisar a quantidade e os tipos de atendimentos a trabalhadores nos CERESTs da região sudoeste. Relata propostas de ações:

O CEREST realiza ações de assistência, formação e educação permanente, informação em saúde, controle social e vigilância em saúde do trabalhador. Atende trabalhadores do setor público e privado, mas não tem como precisar esse número no momento (E7).

7 O DIESAT (Departamento Intersindical de Estudos e Pesquisas de Saúde e dos Ambientes de Trabalho) foi criado em 1980 por iniciativa e necessidade de uma série de entidades sindicais em compreender a importância da luta pela saúde dos trabalhadores (Lacaz, 2000). 
Sobre onde esses trabalhadores são atendidos quando adoecem, o entrevistado relata que:

Quando adoecem, os trabalhadores do setor público são atendidos no CEREST, e os servidores municipais têm também o médico do trabalho da prefeitura. Os exames complementares são realizados na rede SUS. Os trabalhadores do setor privado têm o CEREST e o médico do trabalho da empresa, nos casos em que esta disponibiliza (E7).

Nas instituições públicas estaduais e federais investigadas, foi evidenciado desconhecimento sobre a atenção à saúde do trabalhador. No que diz respeito à efetivação da estruturação prevista na legislação, os relatos colhidos evidenciam que há um movimento em busca da integração das ações de saúde do trabalhador e um desejo do aumento da capacidade de intervenção. Em 2009, a Portaria 2.728/MS normatizou a ampliação da RENAST, do fortalecimento das equipes dos CERESTs, das ações de saúde do trabalhador na atenção básica (Brasil, 2010e). No entanto, as falas mostram que as mudanças necessárias, de fato, ainda não aconteceram na região.

\section{Categoria 2: Ações e diretrizes}

A assistência especializada em saúde do trabalhador continua sendo responsabilidade do CEREST para os 73 municípios da macrorregião. Para as demais ações, como educação em saúde, vigilância em saúde do trabalhador, controle social e informação em saúde, o CEREST presta apoio técnico para os 19 municípios da microrregião (E7).

Um dos papéis do Centro também é esse: tá difundindo pra Secretaria de Saúde dos municípios, pra tá valorizando isso, implementando unidades sentinela, implementando ações dentro da Secretaria de Saúde. [...] O CEREST, esse ano, desenvolveu um trabalho muito interessante de divulgar, de tá divulgando o CEREST, divulgando a temática, que é a saúde do trabalhador, que é uma temática que é pouco conhecida, pouco discutida (E1).

Os relatos reafirmam que a área de abrangência do CEREST da região sudoeste da Bahia é extensa e que a expansão da política de saúde do trabalhador na região está em fase inicial, pois as ações estão ainda voltadas para divulgação e sensibilização visando ao reconhecimento da importância dessa política.

Sobre essa questão, Domingues Júnior (2005) afirma que não é necessário um tratamento especial para o serviço público, basta que a política de saúde do trabalhador seja institucionalizada e capilarizada no âmbito da administração pública.

No comentário seguinte, o entrevistado relata o trabalho de sensibilização dos gestores e funcionários dos municípios e se refere à capacitação que está sendo feita com o objetivo de formar unidades sentinela.

A DIRES tem apoiado o CEREST na formação dessas unidades sentinelas nos municípios [...] A gente chamou, capacitou sobre a formação dessas unidades (E1).

[...] a gente sensibiliza mais essas unidades porque essas unidades estão com o termo de adesão assinado pelo gestor [...] Então ele está com o compromisso [...] (E7).

A capacitação e a sensibilização são ações fundamentais para o desenvolvimento de uma política eficiente, pois preparam os profissionais para uma atuação comprometida. No entanto, entendemos que esse comprometimento diminui se não houver estrutura adequada.

Para Sato et al. (2006), o campo da saúde do trabalhador abre espaço para o desenvolvimento da ciência psicológica na intersecção entre trabalho, organizações e saúde, de forma a facilitar o reconhecimento, por parte dos profissionais de saúde, de que o trabalho pode 
causar adoecimento e para incluir essa visão na sua prática profissional. Os autores também apontam outras formas de atuação do psicólogo nas atividades de educação em saúde, tais como: grupos de formação de profissionais de saúde, grupos com trabalhadores que buscam assistência nos CERESTs ou em atividades para a população em geral.

\section{Categoria 3: Equipes e serviços}

[...] aqui no CEREST [...] a gente tem cinco focos: trabalha com assistência, que é quando o trabalhador tem um acidente de trabalho ou agravo ocupacional [...] ai vai ser fechado um nexo com o médico e tem a educação em saúde [...] e temos a vigilância, que é o nosso foco maior [...] É uma equipe multiprofissional, aqui nós temos psicóloga, enfermeira, fisioterapeuta, dois assistentes sociais, médico do trabalho, técnico de segurança do trabalho, técnico de enfermagem e $o$ pessoal de apoio administrativo [...] a gente emite relatórios para as delegacias regionais do trabalho, para o Ministério do Trabalho e para o Ministério Público, e a gente também orienta [...] (E7).

Ficou evidenciado que a equipe existente mostra-se mínima para atender aos serviços, conforme já apontado em relatos anteriores, o que confirma a indicação de que a política de saúde do trabalhador deve ser capilarizada no âmbito da administração pública, com a atuação dos profissionais de outras unidades de saúde para dar suporte ao CEREST.

Foi apontado que um serviço fundamental e que deve ser desenvolvido por todas as equipes de trabalho é o registro de adoecimentos e acidentes relacionados ao trabalho, sendo sugerido pelo entrevistado que seja compulsório:

Unidade sentinela é um hospital ou uma unidade básica de saúde que vai tá notificando as doenças relacionadas ao trabalho ou os acidentes de trabalho pra registrar. [...] Deve ser hospital público, privado. Eles deveriam estar com a obrigação de notificar. Como, para doenças relacionadas ao trabalho, tem que ter a comprovação, o nexo, e às vezes é difícil o profissional estar capacitado para fazer esse nexo, precisa de capacitação, aí o Ministério da Saúde desenvolveu essa política da unidade sentinela, mas, na realidade, qualquer profissional e qualquer unidade pode tá notificando (E1).

[...] o profissional, principalmente o profissional médico, não tem esse hábito de estar notificando, [...] a gente trabalha o ano inteiro sensibilizando o profissional de saúde para não esquecer de notificar, só que atende [...], mas na hora de notificar, não faz. E a gente fica sem saber. Por isso que os dados estão baixos (E7).

As unidades sentinela são fundamentais, pois constituem a parte da Rede que mantém contato direto com o problema dos agravos à saúde do trabalhador e dos acidentes de trabalho. Ao identificá-los, devem ser feitos o nexo causal e o registro. Sobre esse aspecto, a Portaria MS/GM n 3.120/98, que trata da Vigilância em Saúde do Trabalhador (VISAT), orienta sobre o funcionamento dos sistemas de informação em saúde e sua importância, pois eles permitem detectar e analisar os fatores determinantes e condicionantes dos agravos à saúde relacionados aos processos e ambientes de trabalho e, em consequência, possibilitam planejar, executar e avaliar as intervenções necessárias (Brasil, 2010b).

[...] a gente precisa sensibilizar desde a recepção até o profissional médico, pra que ele coloque o $\mathrm{CID}$, que vai estar identificando esse acidente, pra que posteriormente seja feita a notificação no SINAN [...] porque, se num município tá acontecendo muito acidente, em determinada área, tá acontecendo um elevado número de adoecimento, isso já pode tá pontuando uma necessidade de uma política de saúde naquela área [...] (E1).

Aponta-se a necessidade dos registros para se produzirem dados mensuráveis e de estudos mais amplos para que se conheçam as peculiaridades do trabalho que afetam o 
trabalhador, possibilitando o adoecimento, sendo necessário o envolvimento responsável de todos com relação ao funcionamento dos sistemas de informação.

\section{Categoria 4: Atenção à saúde do servidor público por meio de políticas públicas}

Eu tava até brincando aqui quando eu cheguei [...] não, a gente não tem desenvolvido, porque o papel da saúde do trabalhador aqui na DIRES não é esse papel interno. Aí teria que ter uma política de recursos humanos. A gente não tem. A CESAT também não tem, faz pra fora [...] (E1).

Os depoimentos evidenciam que existe carência de ações em saúde para os servidores públicos, inclusive para os que trabalham na própria área. Nessa mesma direção, Domingues Júnior (2005) comenta que, ao servidor público que tem o Estado como patrão cabe a máxima: "Faça o que te digo, não faça o que eu faço". E complementa, dizendo que "o servidor público alijado de proteção no seu ambiente de trabalho, supervisiona a aplicação das regras de proteção e prevenção, na iniciativa privada" (Domingues Júnior, 2005, p. 54).

Quando solicitados a falar de sua experiência na área e como percebem essa política no município e no órgão no qual trabalham, os depoimentos dos entrevistados que não trabalham na área de saúde do trabalhador evidenciam que têm pouco conhecimento das políticas públicas voltadas para esse fim. Alguns se referem ao CEREST, porém demonstram pouco conhecimento:

Não sei [...] Não me lembro [...] Faz tanto tempo isso, que me parece que eles pediram um espaço aqui pra poder divulgar. Salvo engano foi isso. Então a gente tomou conhecimento, eu tomei conhecimento da existência do CEREST nessa ocasião, que já tem um bom tempo (E5).

Alguns entrevistados demonstraram desconhecer que o CEREST também atende ao servidor público: "O CEREST é exatamente para o trabalhador privado. [...] mas ele, o CEREST, não trabalha com o servidor público" (E4).

Essas informações coincidem com o que relatam os entrevistados que atuam na área de saúde do trabalhador, ao afirmarem que essa é uma temática que precisa ser divulgada e discutida. Domingues Júnior (2005) salienta a necessidade de mais atenção à saúde do servidor público:

[...] não se avaliam as condições de trabalho do servidor, com a desculpa de que, para o servidor, não há perda de salário, pois o Estado continuará pagando, mesmo com o seu afastamento. Assim, com essa desculpa instalada, promoveu-se o definhamento da estrutura destinada a cuidar da manutenção da saúde do servidor [...] Tal situação é comprovada indiretamente pelo elevado índice de aposentadorias por invalidez no serviço público que atingiu seu auge em 2004, com 27,3\% (p. 118).

Entendemos que utilizar-se da desculpa de que o servidor não sofre perda de salário quando adoece configura falta de responsabilidade e zelo com o servidor e com o bem público. $\mathrm{O}$ depoimento a seguir aborda o aspecto do gasto em dobro, que ocorre quando se faz a substituição do profissional. No entanto, mesmo que não haja substituição, existem custos, pois o servidor fica afastado e recebe salário sem dar uma contrapartida em serviços.

Está pagando duas vezes o salário desse profissional. Quando devia cuidar da saúde pra não ter esse desgaste, esses dois custos, não é? O custo do professor substituto e o custo do profissional que está encostado. Por falta de assistência, porque se nós tivéssemos assistência a estes profissionais com certeza eles voltariam (E2). 
Este custo poderia ser revertido para investimentos na área de saúde. Como analisa Domingues Júnior (2005), a não implantação de ações em saúde do trabalhador no serviço público é um preço que todos pagam:

Tal situação atinge diretamente todos os atores envolvidos nesta história de saúde/doença do trabalhador no serviço público [...] Para o servidor, tem-se a redução direta da sua expectativa de vida, ou na melhor das hipóteses uma redução significativa da sua qualidade de vida, tornando-se impedido de realizar tarefas antes desenvolvidas [...] No âmbito da sociedade, temos a redução da eficiência do serviço público, pois o afastamento sobrecarrega os servidores remanescentes, diminuindo ou a qualidade do serviço prestado, ou a quantidade de atendimentos realizados (p. 55).

Dessa forma, apresenta-se uma configuração do adoecimento do servidor que pode refletir para o governo e a sociedade, produzindo, além de perda na qualidade do atendimento, retrabalho, absenteísmo e rotatividade dos servidores. Mas atinge principalmente o servidor:

Que a gente tá aqui, estamos envelhecendo aqui, e a hora que os problemas surgem, nós não temos essa política [...] Uma coisa que às vezes a gente fica [...] A gente ressente. Por exemplo, esse colega que perdeu uma visão, ele tá afastado [...] (E5).

Neste relato, o entrevistado evidencia o sofrimento decorrente de vivenciar com seus pares a falta de atenção e cuidados com a saúde, o que ressalta para nós a necessidade de reconhecimento desse indivíduo que está por trás da máquina pública e que sofre.

\section{Categoria 5: Principais demandas em saúde do trabalhador}

[...] a dificuldade da equipe mínima que tem o CEREST pra atender a 73 municípios, então a gente fica trabalhando, eles ficam, e a Bahia toda, na prioridade da prioridade da prioridade. [...] (E7).

Em 2012 foram concluídos projetos para os fatores de risco que trabalham no setor calçadista e os fatores de risco para trabalhadores com amianto, agrotóxicos, com sílica e com urânio. Tem a questão do ramo calçadista, da construção civil, que acidenta muito. Está na programação para 2013 um projeto com os postos de combustiveis (E7).

Estes depoimentos mostram a necessidade de atenção para diversos setores, e em nenhum momento foi feita referência a demandas do servidor público. $O$ entrevistado enfatiza que a "equipe mínima" do CEREST da região não tem como atender às demandas e cita situações graves. A partir dessa perspectiva, refletimos sobre as condições de outros setores, como o serviço público, que não têm sua necessidade tão exposta, de tal forma que não emerge para o entrevistado. trabalhador:

Abaixo, relato de trabalhador do setor público que não trabalha na área de saúde do

Aqui nós temos casos diversos de adoecimento: o que mais vemos são as "LER/DORT" [...] Tem também diversos casos de depressão, de dependência ao álcool e alguns de câncer. Mas nunca se falou que pode ter algo a ver com o trabalho (E3).

O depoimento acima apresenta uma diversidade de tipos de adoecimento. As notificações estaduais por agravo, no estado da Bahia, registradas no Sistema de Informação de Agravos de Notificação (SINAN-NET), indicam como principais demandas em saúde do trabalhador as Lesões por Esforços Repetitivos (LER), também denominadas Distúrbios 
Osteomusculares Relacionados ao Trabalho (DORT). Excluindo-se os acidentes de trabalho, em segundo lugar, aparecem os transtornos mentais (Brasil, 2010a).

Nas entrevistas, há relatos de problemas que têm maior propensão de existir em determinado setor, como problemas de voz para os professores. Observamos que, em mais de uma instituição, foram verificados casos de depressão, mas é necessário entender que a organização do trabalho é diferente em cada área pública, por isso merece um olhar diferenciado. $O$ mesmo ocorre com LER/DORT, que vai atingir o trabalhador de acordo com a atividade desempenhada por ele.

A gente tem casos de professores que têm problema de LER [...] Nós temos muitos professores com problemas sérios nas cordas vocais. Nós temos alguns casos de professores que perderam a voz [...] o problema mais sério é a questão da depressão [...] (E2).

No serviço público, você tem um trabalho excessivo, uma falta de pessoal, você tem o seu equipamento defasado, algum mobiliário defasado, aí, sim, eu acho que esses problemas podem afetar o psíquico das pessoas, [...] mas é o desgaste físico. [...] tem doença ocupacional, que é o que a gente chama de LER. Então são pessoas que já estão lesionadas e aí, sim, foi por causa do trabalho [...] (E6).

Percebemos com esses depoimentos que se evidencia a necessidade de ampliar a percepção sobre o adoecimento e o que está no campo do cuidado com a saúde do trabalhador, pois nem sempre se reconhece a inter-relação física e psíquica. Ao pesquisar as relações entre saúde mental e trabalho, Dejours (1999) focaliza dinâmicas que conduzem ora ao prazer, ora ao sofrimento, e constata que as consequências desses sentimentos podem seguir diferentes desdobramentos, inclusive culminar em patologia mental ou psicossomática.

Diz ainda que: "Por organização do trabalho designamos a divisão do trabalho, o conteúdo da tarefa (na medida em que ele dela deriva), o sistema hierárquico, as modalidades de comando, as relações de poder, as questões de responsabilidade etc." (Dejours, 1992, p. 25). A organização do trabalho exerce sobre o homem uma ação específica, cujo impacto maior é o aparelho psíquico.

Os relatos dos entrevistados mostram que as pessoas não aderem às ações propostas, como a prática de atividades que previnam a LER/DORT, o que nos leva a inferir que tais propostas não têm significado para esses trabalhadores, conforme percebemos nesta fala: "Aqui tentamos desenvolver atividades de prevenção, como alongamento, "ginástica laboral", mas as pessoas começam e não continuam [...]"(E3).

Configura-se para nós a compreensão de que a realização de discussões no espaço do trabalho visando ao reconhecimento do que produz o adoecimento e à ampliação da compreensão sobre políticas em saúde do trabalhador pode fazer que o indivíduo acredite no que foi construído, pois fará sentido para ele, por ter participado do processo. Alguns entrevistados falam da necessidade de contratação de profissionais que tenham um olhar diferenciado e que possam ajudar a perceber o que a pessoa sente.

[...] temos tentado contratar profissionais, como um psicólogo, um assistente social, para organizar atividades de discussão sobre saúde, mas parece utopia [...] (E3).

Se pudéssemos ter alguém, uma seção, uma contratação pra que a pessoa ficasse aqui durante um ano e a gente buscasse, ou ela fizesse um trabalho de levantamento, de pesquisa aqui dentro pra ver qual a nossa real situação [...] desejo que a gente tivesse aqui, que a nossa área de gestão de pessoas tivesse esse olhar pra o servidor, não como servidor, mas como pessoa (E5).

Santos-Filho aponta que a discussão sobre saúde do trabalhador deve abranger temas como: noção de desgaste e carga de trabalho; organização do trabalho; o conceito de sofrimento e estratégias de defesa (Santos-Filho, 2007). Os depoimentos demonstram o desejo 
de compreender as causas e as consequências do adoecimento. Muitas vezes, o próprio trabalhador é culpabilizado.

\section{Categoria 6: Limites e dificuldades}

A unidade sentinela não onera nada para o município, é só ele sensibilizar os profissionais daquela unidade pra tá atento pra aquele trabalhador, ou seja, basta um médico, uma enfermeira, fazer a pergunta, você trabalha em quê? [...] pra que, quando encaminhar ao médico, que a gente sabe que prontos-socorros, hospitais, a demanda é grande, é acelerada. Então provavelmente passa pelo médico, ele não vai fazer essa pergunta (E1).

Os relatos reafirmam a necessidade de aumento da participação da rede municipal e apontam a falta de um olhar para a saúde do trabalhador por parte dos profissionais. Neste relato observa-se a dificuldade de o médico ter esse olhar nos hospitais, em razão da grande demanda que tem que atender.

Outra situação apresentada que dificulta os cuidados com a saúde do servidor é a falta de verba para essa finalidade: "Pra se ampliar as ações, precisa ampliar as equipes, financiamento" (E1).

Os entrevistados que não trabalham na área de saúde do trabalhador relatam que não há verba para essa atividade no orçamento, já que não se trata da atividade-fim da instituição: "Existe uma dificuldade de dar andamento aos processos de compra de material ou serviços que beneficiem o servidor [...] porque não é a atividade-fim, então não está no orçamento" (E3).

Este é um aspecto específico do setor público. Nesse sentido, Valente fala sobre a centralização do planejamento e decisões na administração pública, observando que, no serviço público, principalmente nas prefeituras e nos municípios, há situações absolutamente imprevistas e que requerem improvisos, mas que seus regulamentos são feitos de forma distante em gabinetes de órgãos de planejamento e dificilmente se prestam a ajudar na hora do contato pessoal e em situações específicas. Afirma que é preciso conceder às pessoas que estão na ponta o direito de ter ideias, de decidir e principalmente de agir. Mas que a situação real é a de sempre estabelecerem-se regras de longe (Valente, 2001).

Outra dificuldade apontada refere-se às constantes mudanças dos gestores, ao contrário do que ocorre no setor privado. Essa falta de continuidade na gestão do serviço público gera a possibilidade do abandono de projeto e ações:

[...] mas nós tínhamos um plano ano passado com o coordenador [...] que saiu. Antes de sair ele tava assim, sonhando um bocado de coisa boa para trabalhar e falar sobre a saúde do trabalhador, mas aí ele mudou para outro setor e houve também a mudança da direção [...] e houve muita mudança e a gente acabou desestruturando o que nós começamos a fazer... (E2).

Compreendemos que este é outro fator característico do setor público e que seu efeito será mais ou menos sentido, de acordo com a afinidade entre o novo gestor e o antecessor.

Outro fator ainda é a burocracia:

A gente tem vontade de fazer, mas esbarra na burocracia [...] (E1).

[...] as coisas aqui são bem mais complicadas do que no setor privado. [...] Então, tudo isso, essa dificuldade, esse negócio de você tá demorando pra se atualizar, isso acarreta, também, a maior incidência de doenças ocupacionais dentro do serviço público (E6).

Uma grande dificuldade que é agravada no setor público refere-se à rigidez de normas, como atestam os depoimentos dos entrevistados E1 e E6 e que evidenciam que o engessamento 
inerente ao setor público dificulta o estabelecimento de ações com maior rapidez, conforme análise de Domingues Júnior (2005):

(...) diferentemente da iniciativa privada, o poder público só pode realizar ou executar ações que estiverem respaldadas em algum ato normativo (princípio da legalidade), assim os princípios universais de proteção e de segurança no trabalho não têm aplicabilidade na esfera da administração pública se não forem recepcionados (2005, p. 55).

Ainda com relação à centralização e à burocracia, os entrevistados relataram sobre a concentração na capital das instituições que realizam a perícia médica no trabalhador adoecido, o que causa grande dificuldade.

Esta pessoa dá entrada aqui, mas a perícia é em Salvador, infelizmente, porque a gente já devia ter pelo menos no estado da Bahia uns cinco polos de perícia médica [...] A coisa é muito burocrática e muito demorada (E2).

Nós temos casos de trabalhadores doentes que estão aqui e que não têm condições de se dirigir a Salvador para passar por perícia médica. Tem casos de pessoas que estão em cidades ainda mais distantes da capital e nem vão. E aí não tem como justificar a falta (E3).

A dificuldade apontada pelos entrevistados E2 e E3 revela-se como aumento do sofrimento para o servidor já adoecido, e, além disso, quando este não comparece à perícia, o agravo à saúde não é registrado nos bancos de dados existentes para tal finalidade.

\section{Categoria 7: Ausência de protocolo e planejamento}

[...] a gente procurou contratar um profissional pra que a gente fizesse a ginástica laboral. Então nós tivemos esse programa aí durante uns três anos [...] Só que, por uma questão burocrática [...] tivemos que suspender esse ano e, com fé em Deus, pretendemos, no próximo ano, já colocar isso ai novamente (E5).

Não temos. Às vezes acontece [...] alguns encontros, alguns cursos que vão de certa forma ajudar, e são convidados alguns gestores e alguns coordenadores para participar desses encontros e repassarem essas informações, mas não é nada de concreto, de palpável, que o resultado é assim imediato (E2).

Os depoimentos evidenciam ausência de um planejamento ou de protocolo para lidar com a saúde do trabalhador. Essa situação é encontrada em todas as instituições pesquisadas. Um dos entrevistados relata que fica à espera de algo que ele não sabe se virá e aborda a situação na perspectiva da fé em Deus.

Visando à organização de ações em saúde do trabalhador, a Portaria/MS nº 3.120/1998, já citada, propõe que, além da incorporação de saberes técnicos e de práticas de diferentes áreas do conhecimento, seja reconhecido o saber dos trabalhadores, considerando-o essencial para o desenvolvimento das ações (Brasil, 2010c). Nessa mesma direção de pensamento, estão autores como Sato et al. (2006) e Santos-Filho (2007). Entendemos que a participação dos servidores públicos no processo de ampliação das políticas de saúde do trabalhador é fundamental, pois são eles que vivenciam as experiências e podem dizer o que sentem e o que os afeta.

[...] ano passado, a gente montou um projeto que teve muito sucesso, foi quando a professora [...] que é coordenadora de educação especial trabalhou com um projeto, o "Cuide bem da sua voz" (E2).

[...] aqui a gente já conseguiu, por exemplo, ter a política de melhorar a posição do trabalhador através de relaxamento e exercício físico e outros tipos de exercício, isso com convênio que nós fizemos com uma faculdade [...] (E4). 
A análise dos relatos dos entrevistados demonstra que a saúde do trabalhador nas instituições tem sido tratada com algumas ações pontuais. Essas ações colaboram para uma percepção errônea da saúde do trabalhador, já que elas se restringem à realização de feiras de saúde, aplicação de vacinas, massagem e outras ações individualizantes:

A gente tenta fazer algo diferente, mas o que o pessoal gosta mesmo é de feira de saúde, com vacinação $[\ldots]$ (E3).

[...] nós estamos tendo uma semana de comemoração do dia do servidor. Aí nós já fizemos várias atividades, e hoje nós temos aí a massagem e nós temos uma pessoa aferindo pressão [...] (E5).

Em algumas instituições, os entrevistados apresentaram projetos internos de atenção à saúde do trabalhador. Segundo Sato et al. (2006), ações em saúde do trabalhador têm maior garantia de serem implementadas se houver a participação dos trabalhadores, por permitem maior possibilidade de se conhecer a situação real e, quando os trabalhadores participam da elaboração, eles se tornam fiscais permanentes delas.

\section{Conclusão}

Este estudo buscou compreender como são percebidas as políticas em saúde do trabalhador do serviço público em um município da região sudoeste da Bahia, a partir da ótica dos servidores. Nossa proposta de pesquisa não se estende ao tema da saúde do trabalhador do setor privado, uma vez que nosso objetivo é o servidor público e os investimentos em sua saúde. Para isso, buscamos aprofundar o conhecimento sobre o tema, a partir de pesquisa bibliográfica e de campo, realizada em instituições públicas de um município do sudoeste da Bahia.

Foi constatada a existência de ações no âmbito do funcionalismo público federal, como o Subsistema Integrado de Atenção à Saúde do Servidor (SIASS) e as pesquisas realizadas na Universidade de Brasília (UNB). No entanto, os dados coletados demonstram que essas iniciativas não alcançam os servidores pesquisados.

A investigação permitiu aumentar a percepção sobre a implantação da política de saúde do trabalhador na região, ficando evidenciada a necessidade de ampliação das ações. Foi relatado que a equipe do CEREST da região sudoeste não tem como atender às demandas e que estão trabalhando com as maiores prioridades, sendo citadas demandas do setor privado. Foi sugerida a implantação de pelo menos mais dois CERESTs e o envolvimento da rede de saúde municipal, com incorporação de ações em saúde do trabalhador na prática diária, e não apenas concentradas nos CERESTs.

Nas instituições que desenvolvem atividades voltadas para essa área, nota-se que o foco principal é a prevenção nos ambientes de trabalho, e não se observa nessas instituições a existência de políticas específicas para o servidor público, inclusive da própria instituição. Em consonância com esses dados, nas instituições públicas que não são da área de saúde, foram constatados pouco conhecimento sobre as políticas públicas existentes e carência de ações em saúde do trabalhador.

Entendemos que, para a ampliação das ações, é indispensável dar visibilidade à demanda de políticas em saúde do trabalhador, com a apresentação de dados mensuráveis. Esta medida permite conhecer que tipo de adoecimento acomete uma população, o que possibilita o adequado planejamento de estratégias de prevenção e controle dos agravos. Nesse sentido, um fator limitante é a falta de notificação das doenças e acidentes de trabalho por parte de hospitais e clínicas. 
Foram evidenciadas outras limitações inerentes à estrutura da administração pública, tais como a burocracia, a centralização de planejamento, a mudança de gestores e a descontinuidade das ações. A maior dificuldade assinalada nas instituições que não atuam na área de saúde do trabalhador refere-se à ausência de protocolo e planejamento para as ações em saúde para o servidor público. A saúde do trabalhador nessas instituições tem sido tratada com algumas ações pontuais e individualizantes, que colaboram para uma percepção errônea da questão.

Constatamos que a política interna em saúde do trabalhador não existe nas instituições públicas ou está em estado embrionário. Para a construção dessa política interna, compreendemos que é fundamental a existência de um espaço para discussão sobre o tema, com participação de gestores e servidores, reconhecendo a necessidade de inserir os servidores no espaço de discussão e deliberação, entendendo ser uma forma produtiva de proteger-se do sofrimento. Dessa forma, os trabalhadores podem pensar sua realidade e buscar a ampliação das políticas em saúde. Por isso, é importante a atuação de profissionais que tenham "o olhar" de atenção à saúde do trabalhador, um campo para atuação de psicólogos.

Como caminhos para superar os obstáculos, ressaltamos a divulgação e a discussão sobre o tema nas instituições públicas, possibilitando o reconhecimento do sofrimento e a criação de ações para lidar com esse fenômeno. Esta proposta é importante para todas as instituições e especialmente para as que podem desenvolver ações para seus servidores e também para trabalhadores externos, a exemplo das prefeituras. Refletimos que, com a divulgação das políticas públicas, haverá aumento de demandas. Por outro lado, é exatamente o reconhecimento das demandas, somado à participação dos servidores nas discussões, que pode pressionar para que as políticas públicas sejam ampliadas e para que seja assegurada sua manutenção.

Compreendemos que o atual conceito de saúde do trabalhador representa um avanço ao trazer uma política com visão diferenciada sobre saúde/doença para além da assistência. As instituições e profissionais de saúde também devem se considerar como objeto de análise, repensando continuamente sua prática, de forma a alcançar e fazer sentido para todos os envolvidos: gestores públicos, profissionais de saúde e trabalhadores. Portanto, são fundamentais a divulgação e a discussão com participação de todos os responsáveis e interessados em políticas de atenção à saúde deste que trabalha servindo ao público.

\section{Referências}

Antunes, R. (2005). O caracol e sua concha: ensaio sobre a nova morfologia do trabalho. São Paulo: Boitempo.

Bahia. (2010). Programa de Atenção à Saúde do Trabalhador. Disponível na Internet: www.saude. ba.gov.br/int_obj.html [setembro 2010]

Brasil (2001). Doenças relacionadas ao trabalho: manual de procedimentos para os serviços de saúde. Brasília: Ministério da Saúde do Brasil. Disponível na Internet: www.opas.org.br/sistema/arquivos/Saudedotrabalhador.pdf [agosto 2010]

Brasil (2006). Constituição da República Federativa do Brasil (39ạ ed.). São Paulo: Saraiva.

Brasil (2010a). Notificações estaduais por agravo. Brasília: Ministério da Saúde do Brasil. Disponível na Internet: portal.saude.gov.br/portal/arquivos/pdf/notificacoes_agravos_br_0411_st_2009.pdf [outubro 2010]

Brasil (2010b). Portaria 1.679/GM.2002. Brasília: Ministério da Saúde do Brasil. Disponível na Internet: dtr2001.saude.gov.br/sas/portarias/port2002/GM/GM-1679.htm [setembro 2010]

Brasil (2010c). Política Nacional de Saúde do Trabalhador. Brasília: Ministério da Saúde do Brasil. Disponível na Internet: portal.saude.gov.br/portal/saude/visualizar_texto.cfm?idtxt=30426\&janela $=1$ [outubro 2010] 
Brasil (2010d). Portaria 3.120/98. Brasília: Ministério da Saúde do Brasil. Disponível na Internet: www.pgt.mpt.gov.br/images/arquivos/codemat/ms/Portaria_3120_GM.pdf [outubro 2010]

Brasil (2010e). Portaria 2.728/09. Brasília: Ministério da Saúde do Brasil. Disponível na Internet: portal.saude.gov.br/ portal/arquivos/pdf/portaria_renast_2728.pdf [outubro 2010]

Brasil (2011). Todos usam o SUS! SUS na Seguridade Social, Política Pública e Patrimônio do povo brasileiro. Brasília: Ministério da Saúde do Brasil. Disponível na Internet: www.conselho.saude.gov.br/14cns/doc_ orientador.html [dezembro 2012]

Brasil (2012a). Saúde do servidor - nosso compromisso, nossas conquistas, nossos desafios. Brasília: Ministério da Saúde do Brasil. Disponível na Internet: portalsipec.planejamento.gov.br/clientes/sipec/sipec/eventos/iii-enass-eii-forum-de-saude-mental-na-apf [dezembro 2012]

Brasil (2012b). IV Encontro Nacionais de Atenção à Saúde do Servidor-ENASS. Brasília: Ministério da Saúde do Brasil. Disponível na Internet: portalsipec.planejamento.gov.br/eventos/iv-encontro-nacional-de-atencao-asaude-do-servidor-enass [dezembro 2012]

Brasil (2012c). Subsistema Integrado de Atenção à Saúde do Servidor. Brasília: Ministério da Saúde do Brasil. Disponível na Internet: www2.siapenet.gov.br/saude/portal/public/consultaPublica/loginCidadao.xhtml [dezembro 2012]

Dallari, A. A. (1989). O que é funcionário público. São Paulo: Brasiliense.

Dejours, C. (1986). Por um novo conceito de saúde. Revista Brasileira de Saúde Ocupacional, 14 (54), 7-11.

Dejours, C. (1992). A loucura do trabalho: estudo de psicopatologia do trabalho (5aㅡ ed.). São Paulo: Cortez-Oboré.

Dejours, C. (1999). Conferências brasileiras: identidade, reconhecimento e transgressão no trabalho (A. C. F. Reis, trad.). São Paulo: Fundap, EAESP/FGV.

Domingues Júnior, L. R. P. (2005). O processo saúde-doença no serviço público e suas consequências ao Estado, ao cidadão e ao servidor. In III Conferência Nacional de Saúde do Trabalhador (pp. 54-55).

Ferreira, M. C. (2011). Qualidade de vida no trabalho: uma abordagem centrada no olhar dos trabalhadores. Brasília: Edições Ler, Pensar, Agir.

Ferreira, M. C., Alves, L. \& Tostes, N. (2009). Gestão de qualidade de vida no trabalho (QVT) no serviço público federal: o descompasso entre problemas e práticas gerenciais. Psicologia: Teoria e Pesquisa, 25 (3), 319-327.

Ferreira, M. C., Antloga C., Ferreira, R. R. \& Bergamaschi, A.V. (2009). In Anais da 61̊ㅗ Reunião Anual da SBPC. Manaus.

Godoy, A. S. (1995). Pesquisa qualitativa: tipos fundamentais. Revista de Administração de Empresas, 35 (3), 20-29.

Gomez, C. M. \& Thedim-Costa, S. M. F.(1999). Precarização do trabalho e desproteção social: desafios para a saúde coletiva. Ciência e Saúde Coletiva, 4 (2), 411-421.

Lacaz, F. A. C. (2000). O SUS deve efetivamente incorporar o atendimento à saúde do trabalhador. Informativo Diesat, 8.

Lacaz, F. A. C. (2005). Saúde do Trabalhador: vinte anos de história e trajetória. In III Conferência Nacional de Saúde do Trabalhador (pp. 56-59). Brasília: Ministério da Saúde.

Machado, L. (2007). Usos sociais do trabalho e da noção de competências. In H. Hirata \& L. Segnini (Orgs.), Organização, trabalho e gênero. São Paulo: Senac.

Meirelles, H. L. (2008). Direito administrativo brasileiro (34를 ed.) São Paulo: Malheiros Editores.

Mendes, A. M. \& Araújo, L. K. R. (2011). Clínica psicodinâmica do trabalho: práticas brasileiras. Brasília: Ex Libris.

Merlo, A. R. C. \& Lápis, N. L. (2007). A saúde e os processos de trabalho no capitalismo contemporâneo: reflexões na interface da sociologia do trabalho e da psicodinâmica do trabalho. Psicologia $\mathbb{E}$ Sociedade, 19 (1), 61 . 68 .

Oliveira, G. S. \& Cunha, A. M. O. (2006). Breves considerações a respeito da fenomenologia e do método fenomenológico. In A. A. Bello (Org.), Introdução à fenomenologia. Bauru: Edusc.

Paim, J. S. (2007). Reforma sanitária brasileira: contribuição para a compreensão e crítica. Tese de Doutorado, Instituto de Saúde Coletiva, Universidade Federal da Bahia, Salvador.

Reis. L. M. (2010). Sexualidade e câncer de colo de útero: o corpo feminino adoecido na perspectiva de Maurice MerleauPonty. Tese de Doutorado, Faculdade de Filosofia, Ciências e Letras de Ribeirão Preto, Universidadse de São Paulo, São Paulo. 
Santos-Filho, S. B. (2007). Um olhar sobre o trabalho em saúde nos marcos teórico-políticos da saúde do trabalhador e do HumanisaSUS. Artigo disponível na Internet: bvsms.saude.gov.br/bvs/publicacoes/olhar_sobre_trabalho.pdf [setembro 2010]

Sato, L., Lacaz, F. A. C. \& Bernardo, M. H. (2006). Psicologia e saúde do trabalhador: práticas e investigações na Saúde Pública de São Paulo. Estudos de Psicologia (Natal), 11 (3), 281-288.

Sennett, R. (1999). A corrosão do caráter: consequências pessoais do trabalho no novo capitalismo. Rio de Janeiro: Record.

Simões, S. M. F. \& Souza, I. E. O. (1997). Um caminhar na aproximação da entrevista fenomenológica. Revista Latinoamericana de Enfermagem, 5 (3), 13-17.

Valente, A. (2001). Governo empreendedor e estado-rede na gestão pública brasileira. In A gestão pública: desafios e perspectiva (Cadernos FLEM 1, pp. 78-103). Salvador: Fundação Luís Eduardo Magalhães.

\section{Endereço para correspondência}

zsouza@sefaz.ba.gov.br, leliareis@yahoo.com.br

Recebido em: 15/05/2012

Revisado em: 31/12/2012

Aprovado em: 31/01/2013 